\title{
PENGARUH BUDAYA ORGANISASI DAN LINGKUNGAN ORGANISASI TERHADAP KEPUASAN KERJA DAN KOMITMEN ORGANISASI
}

\author{
Dwi Junianto ${ }^{1}$, Joko Sabtohadi ${ }^{2}$ \\ 1,2STIE Perbanas Surabaya, Balitbangda Kabupaten Kutai Kertenagara \\ email:1junianto97@gmail.com, 2sabtohadijoko@yahoo.co.id,
}

Kata kunci :

Lingkungan Organisasi, Budaya

Organisasi, Kepuasan Kerja,

Komitmen Organisasi

Keywords: organizational climate, organizational culture, Job Satisfaction, Organizational Commitment

Dwi Junianto, \& Joko Sabtohadi. (2019) Pengaruh budaya organisasi dan lingkungan organisasi terhadap kepuasan kerja dan komitmen organisasi. Jurnal Akuntabilitas: Jurnal IlmuIlmu Ekonomi, 12(2), 12-22.

\begin{abstract}
ABSTRAK
Penelitian ini bertujuan menganalisis tentang pengaruh lingkungan organisasi dan budaya organisasi terhadap kepuasan kerja serta komitmen organisasi pada karyawan PT. Wahyu Daya Mandiri. Penelitian eksplanatory yaitu penelitian untuk mengetahui dan menjelaskan pengaruh antar variabel untuk menguji suatu teori atau hipotesis. Alat analisis menggunakan Smart-PLS 3.2.8 dengan metode penelitian adalah metode kuantitatif analisis jalur. Sampel dalam penelitian ini diambil sebanyak 34 dan menggunakan sampling jenuh atau sensus, yaitu karyawan PT. Wahyu Daya Mandiri yang diminta untuk memberi respon kuesioner. Hasil penelitian membuktikan lingkungan organisasi, budaya organisasi berpengaruh secara signifikan dan positif terhadap kepuasan karyawan pada karyawan PT. Wahyu Daya Mandiri Surabaya dan budaya organisasi dan kepuasan karyawan berpengaruh positif signifikan terhadap komitmen organisasi.
\end{abstract}

\section{ABSTRACT}

This study is aimed at investigating the effect organizational environment and organizational culture on job satisfaction and organizational commitment on PT Wahyu Daya Mandiri employes. The exploratory study to investigation to find out and explain the influence of variables aimed at testing the theory or hypothesis. The analytical tools using Smart-PLS 3.2.8 and the research method used is quantitative of path analysis. The sample in this study was taken 34 and used saturated or census sampling, which is PT Wahyu Daya Mandiri employes request to respond to the questionnaire. The results show that organizational culture, organizational climate have a positive significant impact on job satisfaction in PT Wahyu Daya Mandiri and organization culture, job satisfaction have a positive significant on organizational commitment.

\section{PENDAHULUAN}

Persaingan industri pun semakin ketat untuk mengejar dan mengimbangi perkembangan industri saat ini, sehingga dapat bertahan dan bahkan terus tumbuh 
berkembang. Banyak perusahaan yang telah berinovasi terhadap kualitas layanan untuk memenuhi kepuasan konsumen.

Selain itu juga strategi yang diterapkan adalah melalui pemberdayaan sumber daya manusia. Hal ini akan terlihat apabila perusahaan dapat mengelola sumber daya manusia tentunya dapat meningkatkan efisiensi dan efektifitas. Dessler (2016:3) menjelaskan bahwa manajemen sumber daya manusia merupakan proses agar mendapatkan, melatih, menilai serta memberikan kompensasi pegawai, juga agar mengurus relasi karyawan mereka, kesehatan juga keselamatan karyawan, dan berbagai hal yang memiliki hubungan dengan keadilan.

Berdasarkan observasi lapangan yang dilakukan diketahui bahwa ada beberapa permasalahan yang terjadi karena adanya perubahan organisasi yang sifatnya mendadak dan keyakinan perbaikan yang akan terjadi dengan perubahan organisasi ini. Dengan adanya perubahan yang dilakukan akan membawa dampak diantaranya adalah berhubungan dengan permasalahan komitmen karyawan pada organisasi.

Lingkungan kerja dapat berupa lingkungan tangible (fisik) dan lingkungan intangible (non fisik). Karyawan membutuhkan suasana kerja yang kondusif, nyaman yang dapat menimbulkan situasi dalam bekerja terbina dalam hubungan yang harmonis. Tentunya lingkungan kerja tersebut harus diwujudkan untuk menciptakan quality of work life.

Susanty (2013) dalam penelitiannya bahwa setiap organisasi tentunya mempunyai iklim berbeda-beda yang akan memberikan pengaruh tingkah laku manusia dalam organisasi perusahaan. Lingkungan organisasi akan tampak dari bagaimana karyawan dihargai, diarahkan oleh perusahaan dan dibina. Semakin tinggi perhatian akan lingkungan organisasi maka semakin tinggi pula komitmen organisasi.

Terdapat implikasi strategis bahwasannya indikator dukungan organisasi menjadi faktor penting didalam memberikan peningkatan lingkungan organisasi yang bagus. Dengan adanya sikap saling mendukung antar sesama karyawan CV. Wiracana maka iklim organisasi mampu terbentuk dengan baik, sehingga hal tersebut patut dipertahankan (kadek, 2019) 
Budaya organisasi mencerminkan sikap, nilai-nilai dan perilaku anggota dalam organisasi yang mendeskripsikan karakteristik dari organisasi dan menjadikan factor pembeda dengan organisasi lainnya.

Bahklan budaya ini penting untuk dipahami anggotanya sekaligus harus diterima dan disampaikan saat mulai proses rekruitmen sehingga calon pegawai menyadari bahwa ia akan memasuki suatu arena yang berbeda dengan segala tantangannya (Rahmawati et al., 2019).

Kepuasan kerja mendeskripsikan perasaan seseorang dengan pekerjaannya. Celluci dan De Vries (1978), dalam Fuad Mas'ud (2004), merumuskan indikatorindikator kepuasan kerja dalam 5 indikator sebagai berikut : Kepuasan gaji, promosi, rekan kerja, penyelia, dan pekerjaan itu sendiri.

Kepuasan kerja menjadi indikator penilaian kinerja karyawan sehingga perhatian terhadap karyawan ditempat kerja, pemberian penghargaan, kesesuaian gaji dengan pekerjaan, hubungan yang baik dengan rekan kerja akan mampu meningkatkan daya saing perusahaan.

Komitmen organisasi mencirikan kesetiaan pegawai dalam organisasi dan akan mempertahankan keanggotaannya. Komitmen pegawai tersebut timbul adanya rasa memiliki melalui perasaan positif pada organisasi (afektif). Mereka sadar akan biaya jika meninggalkannya lebih besar daripada manfaat yang diperoleh (normative).

\section{METODE PENELITIAN}

\section{Rancangan Penelitian}

Berdasarkan bentuk data yang diamati pada penelitian ini, maka penelitian ini dikategorikan sebagai penelitian jenis survei. Penelitian survei adalah disebut sebagai explanatory research. Pengumpulan data pokok dilakukan dengan menggunakan angket/kuisioner. Objek penelitian dilakukan di perusahaan PT. Wahyu Daya Mandiri Surabaya. Metode sensus dipergunakan dalam teknik pengambilan sampel yaitu semua anggota populasi karyawan PT. Wahyu Daya Mandiri yang berjumlah 34 responden. 


\section{Kerangka Konsep Penelitian}

Adapun kerangka konsep penelitian dapat dilihat pada gambar 1 sebagai berikut :

\section{Gambar 1}

Kerangka konsep penelitian

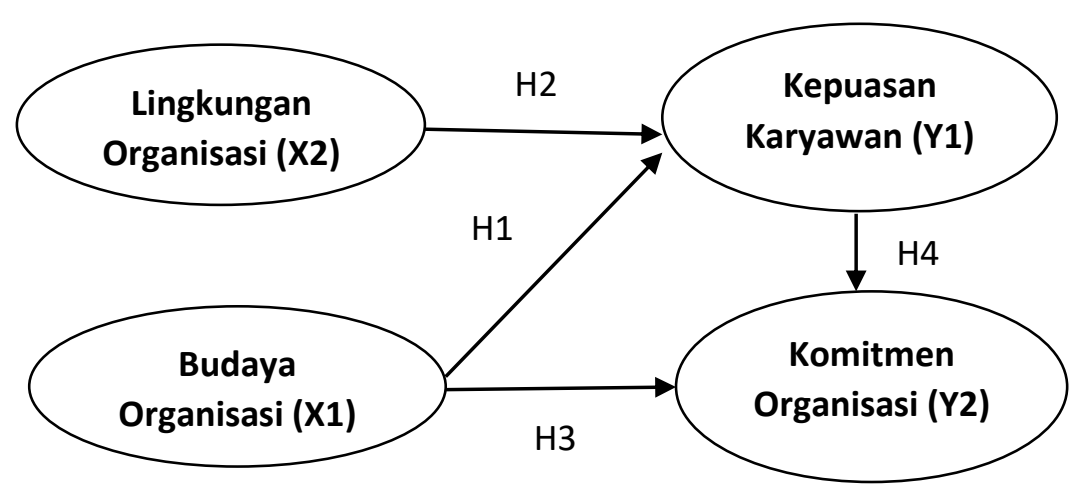

\section{TEKNIK ANALISIS DATA}

Teknik analisis data menggunakan konsep structural equation modeling (SEM) dengan bantuan software SmartPLS 3.2.8 Instrumen penelitian mempergunakan kuesioner untuk dijawab oleh karyawan PT. Wahyu Daya Mandiri. Skala likert digunakan sebagai pengukuran dari skor 1 (sangat tidak setuju) sampai skor 5 (sangat setuju). Berikut ini disajikan pada tabel 1 tentang hasil pengujian validitas dan realibilitas pada instrumen penelitian sebagai berikut :

\section{Tabel 1}

Hasil Uji Validitas dan Realibilitas Instrumen Penelitian

\begin{tabular}{|c|c|c|c|c|c|}
\hline Variabel & $\begin{array}{l}\text { Koefisien } \\
\text { Korelasi }\end{array}$ & Signifikansi & $\begin{array}{c}\text { Keputusan } \\
\text { Validitas }\end{array}$ & $\begin{array}{c}\text { Cronbach's } \\
\text { Alpha }\end{array}$ & $\begin{array}{l}\text { Keputusan } \\
\text { Reliabilitas }\end{array}$ \\
\hline \multicolumn{6}{|c|}{ Budaya Organisasi (X1) } \\
\hline $\mathrm{X} 1.1$ & 0,597 & 0,000 & Valid & \multirow{3}{*}{0,651} & \multirow{3}{*}{ Reliabel } \\
\hline $\mathrm{X} 1.2$ & 0,537 & 0,000 & Valid & & \\
\hline $\mathrm{X} 1.3$ & 0,491 & 0,000 & Valid & & \\
\hline \multicolumn{6}{|c|}{ Lingkungan Organisasi (X2) } \\
\hline $\mathrm{X} 2.1$ & 0,757 & 0,000 & Valid & \multirow{3}{*}{0,898} & \multirow{3}{*}{ Reliabel } \\
\hline $\mathrm{X} 2.2$ & 0,641 & 0,000 & Valid & & \\
\hline$X 2.3$ & 0,723 & 0,000 & Valid & & \\
\hline
\end{tabular}




\begin{tabular}{|c|c|c|c|c|c|}
\hline $\mathrm{X} 2.4$ & 0,648 & 0,000 & Valid & & \\
\hline \multicolumn{6}{|c|}{ Kepuasan Karyawan (Y1) } \\
\hline Y1.1 & 0,784 & 0,000 & Valid & \multirow{4}{*}{0,885} & \multirow{4}{*}{ Reliabel } \\
\hline $\mathrm{Y} 1.2$ & 0,668 & 0,000 & Valid & & \\
\hline Y1.3 & 0,815 & 0,000 & Valid & & \\
\hline Y1.4 & 0,633 & 0,000 & Valid & & \\
\hline \multicolumn{6}{|c|}{ Komitmen Organisasi (Y2) } \\
\hline Y2.1 & 0,653 & 0,000 & Valid & \multirow{3}{*}{0,742} & \multirow{3}{*}{ Reliabel } \\
\hline$Y 2.2$ & 0,610 & 0,000 & Valid & & \\
\hline$Y 2.3$ & 0,691 & 0,000 & Valid & & \\
\hline
\end{tabular}

Sumber : data diolah (2019)

\section{PEMBAHASAN}

\section{A. Model Pengukuran atau Outer Model}

Evaluasi terhadap Outer Model dilakukan dengan 3 cara, yaitu dengan Convergent validity, Discriminant Validity dan Composite Reliability

\section{Convergent validity}

Validitas dinilai dengan cara melihat convergent validity (besarnya original sample estimate/loading factor untuk masing-masing konstruk). Loading factor diatas 0.70 sangat direkomendasikan. Terlihat bahwa terdapat indikator pada gambar 2 yaitu indikator X1.1 mempunyai loading factor dibawah 0,70 sehingga harus didrop atau eliminasi.

\section{Gambar 2}

Hasil nilai loading factor sebelum eliminasi

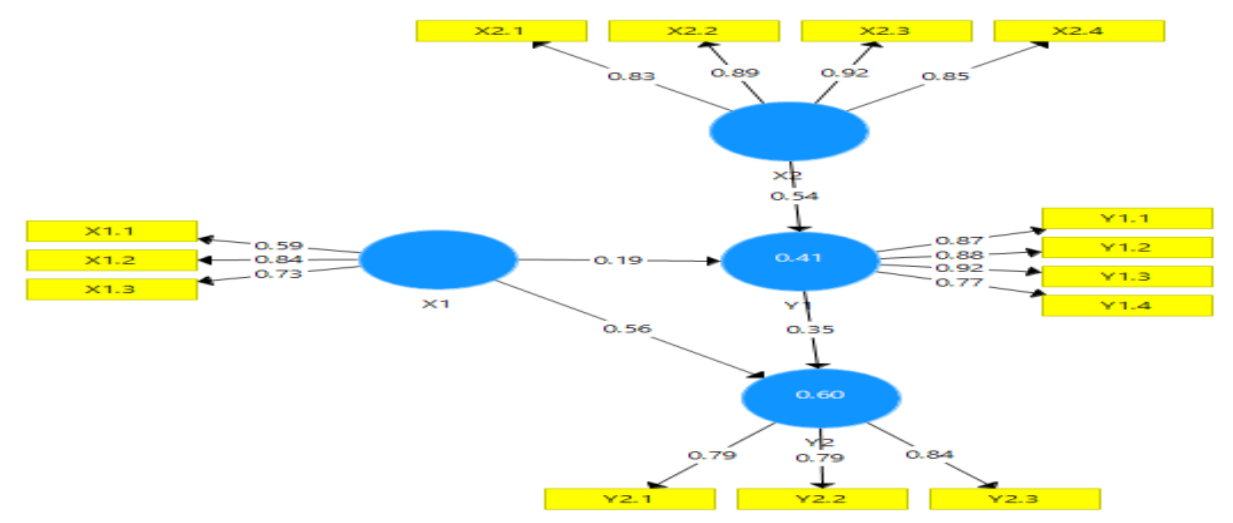

Sumber : data diolah (2019) 
Kemudian di lakukan calculate lagi dan didapatkan hasil pada gambar 2 sebagai berikut :

\section{Gambar 3}

Hasil nilai loading factor setelah eliminasi

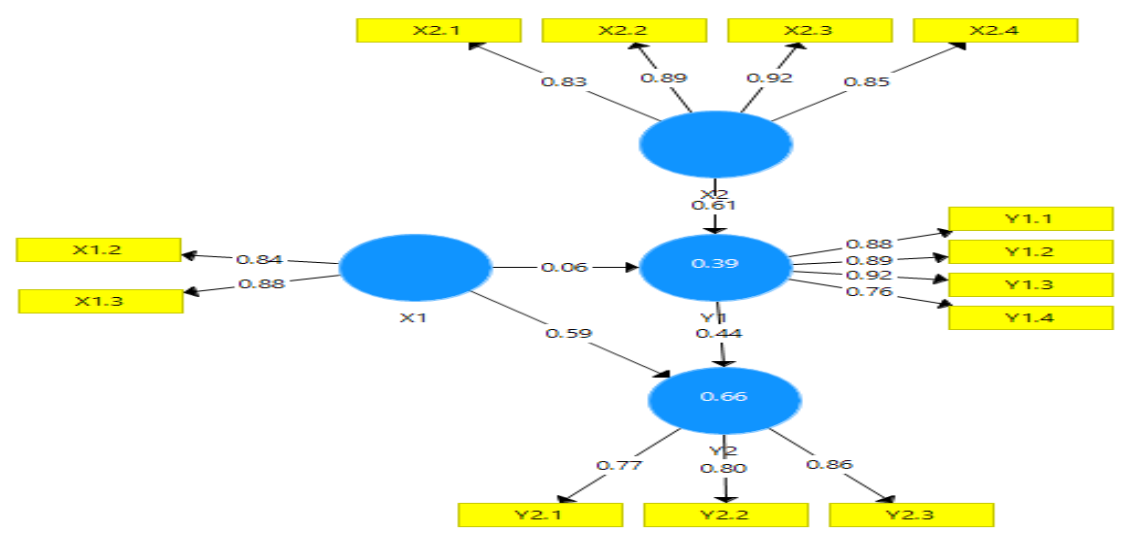

Sumber data : diolah (2019)

\section{Discriminant Validity}

Untuk mengetahui variabel dapat dikatakan Discriminant Validity dapat dilihat dari nilai average variance extracted (AVE). Konstruk dengan validitas yang baik dipersyaratkan nilai AVE harus diatas 0.50 .

Tabel 2

Nilai AVE

\begin{tabular}{|c|c|c|}
\hline Variabel & AVE & Keputusan \\
\hline X1 & 0,742 & Valid \\
\hline X2 & 0,764 & Valid \\
\hline Y1 & 0,747 & Valid \\
\hline Y2 & 0,657 & Valid \\
\hline
\end{tabular}

Sumber : data diolah (2019)

\section{Composite Reliability}

Untuk mengetahui reliabilitas semua konstruk dapat dilihat dari nilai composite reliability. Konstruk reliabel jika nilai composite reliability diatas 0.70 . Hasil 
output menunjukkan seluruh konstruk pada variabel memiliki nilai Composite Reliability $>0.70$, dengan keterangan tabel 3 sebagai berikut :

Tabel 3

Composite Realibility

\begin{tabular}{|c|c|c|}
\hline Variabel & $\begin{array}{c}\text { Composite } \\
\text { Realibility }\end{array}$ & Keputusan \\
\hline X1 & 0,852 & Realibel \\
\hline X2 & 0,928 & Realibel \\
\hline Y1 & 0,922 & Realibel \\
\hline Y2 & 0,851 & Realibel \\
\hline
\end{tabular}

Sumber : data diolah (2019)

\section{Model Pengukuran atau Inner Model}

\section{Pemeriksaan Goodness of Fit Model}

Pemeriksaan model dapat dilakukan dengan adalah dengan melihat dari $\mathrm{R}^{2}$, $\mathrm{Q}^{2}$. Tidak ada acuan umum dalam interpretasi nilai $\mathrm{R}^{2}$ dan didasarkan pada disiplin ilmu masing-masing Pada penelitian ini, model struktural dievaluasi dengan memperhatikan $R$-square $\left(\mathrm{R}^{2}\right)$ dan Stone-Geisser's $\mathrm{Q}^{2}$ (predictive relevance). Penilaian $\mathrm{Q}^{2}$ didasarkan pada koefisien determinasi $\left(\mathrm{R}^{2}\right)$ seluruh variabel endogen. Besaran $\mathrm{Q}^{2}$ memiliki nilai dengan rentang $0<\mathrm{Q}^{2}<1$, semakin mendekati nilai 1 berarti model semakin baik.

Dilihat dari nilai $\mathrm{R}^{2}$ (R-square) artinya model dapat menjelaskan fenomena atau variasi Komitmen Organisasi dapat dijelaskan oleh Budaya Organisasi (X1), Lingkungan Organisasi (X2), Kepuasan Karyawan (Y1), sebesar 66.60\%, sedangkan $33,40 \%$ dijelaskan oleh variabel lain diluar yang di teliti.

Tabel 4

Koefisien R-square

\begin{tabular}{|c|c|}
\hline Variabel & R-square \\
\hline Y1 & 0,390 \\
\hline Y2 & 0,660 \\
\hline
\end{tabular}

Sumber : data diolah (2019)

Jadi, Q2 (predictive relevance) pada model structural nilainya dihitung menggunakan formulasi sebagai berikut : 


$$
\begin{aligned}
\mathrm{Q}^{2} & =1-\left(1-\mathrm{R}_{1}^{2}\right)\left(1-\mathrm{R}_{2}^{2}\right) \\
& =1-(1-0,390)(1-0,660) \\
& =0,7926
\end{aligned}
$$

Hasil perhitungan menunjukkan nilai $\mathrm{Q}^{2}$ sebesar 0.7926 atau nilai prediksi relevance model adalah sebesar 79,26 \% atau artinya sudah baik.

\section{Pengujian t-test}

Hasil pengujian t-test pada masing-masing jalur dapat dilihat pada tabel $5 \mathrm{di}$ bawah ini :

Table 5

Hasil Nilai t-test

\begin{tabular}{|l|c|c|c|l|}
\hline & $\begin{array}{c}\text { Original } \\
\text { Sample }(\mathrm{O})\end{array}$ & $\begin{array}{c}\text { T Statistics } \\
(\mid \mathrm{O} / \text { STDEV } \mid)\end{array}$ & P Values & Keputusan \\
\hline X1- >Y1 & 0,059 & 2,316 & 0,000 & H1 diterima \\
\hline X2- >Y1 & 0,605 & 3,311 & 0,001 & H2 diterima \\
\hline X1- >Y2 & 0,587 & 4,210 & 0,000 & H3 diterima \\
\hline Y1- >Y2 & 0,441 & 4,146 & 0,000 & H4 diterima \\
\hline
\end{tabular}

Sumber : data diolah (2019)

Skor koefisien path atau inner model yang ditunjukkan oleh nilai T-statistic harus diatas 1.96 untuk hipotesis dua ekor (two-tailed) dan diatas 1.64 untuk hipotesis satu ekor (one-tailed) untuk pengujian hipotesis pada alpha 5 persen Jogiyanto (2011: 86). Dalam penelitian ini ditetapkan nilai tingkat signifikansi sebesar $5 \%$ ( $p$-value $<0,05)$.

\section{Pengaruh Budaya Organisasi (X1) Terhadap Kepuasan Karyawan (Y1)}

Pengujian pengaruh Budaya Organisasi terhadap Kepuasan Karyawan dijelaskan pada tabel 5 mengindikasikan Budaya Organisasi berpengaruh signifikan dan positif terhadap Kepuasan Karyawan. Nilai koefisien jalur (path) yang ditunjukkan Budaya Organisasi ke Kepuasan Karyawan 0,059 dan nilai t-statistik sebesar 2,316 (>t - tabel 1,96). 
Hal ini memiliki makna bahwa peningkatan Budaya Organisasi semakin tinggi berarti pula dapat meningkatkan Kepuasan Kerja. Hasil penelitian ini sesuai dengan yang dilakukan oleh (Syaharuddin Y, 2019), (Rieka Reskantika., Ardi Paminto, \& Yana Ulfah, 2019).

\section{Pengaruh Lingkungan Organisasi (X2) Terhadap Kepuasan Karyawan (Y1)}

Pengujian pengaruh Lingkungan Organisasi terhadap Kepuasan Kerja dijelaskan pada tabel 5 mengindikasikan Lingkungan Organisasi berpengaruh signifikan dan positif terhadap Kepuasan Kerja. Nilai koefisien jalur (path) ditunjukkan Lingkungan Organisasi ke Kepuasan Kerja 0,605 dan nilai t-statistik sebesar 3,311 (> t-tabel 1,96).

Hal ini memiliki makna bahwa peningkatan Lingkungan Organisasi semakin baik berimbas pada peningkatan Kepuasan Kerja. Hasil penelitian ini sesuai dengan yang dilakukan oleh (Agustina Wijayanty, 2018), (Erni Aprida Hasibuan \& Afrizal, 2019), (Amirul Fahmi \& Misti Hariasih, 2016).

\section{Pengaruh Budaya Organisasi (X1) Terhadap Komitmen Organisasi (Y2)}

Pengujian pengaruh Budaya Organisasi terhadap Komitmen Organisasi sesuai hasil tabel 5 menginterpretasikan Budaya Organisasi berpengaruh signifikan dan positif terhadap Komitmen Organisasi. Nilai koefisien jalur (path) Budaya Organisasi ke komitmen Organisasi sebesar 0,587 dan nilai t-statistik sebesar 4,210 (> $\mathrm{t}$ - tabel 1,96).

Hal ini mengidikasikasikan bahwa peningkatan Budaya Organisasi akan menyebabkan terjadinya peningkatan Komitmen Organisasi. Hasil penelitian ini sesuai dengan yang dilakukan oleh (Dwiyekti Agung Nugroho, 2011), (Rina Maretasari, 2016) dan (Prayogi Muhamad \& Farlianto, 2016).

\section{Pengaruh Kepuasan Karyawan (Y1) Terhadap Komitmen Organisasi (Y2)}

Pengujian pengaruh Kepuasan Kerja terhadap Komitmen Organisasi dijelaskan pada tabel 5 menginterpretasikan Kepuasan Kerja berpengaruh signifikan dan positif terhadap Komitmen Organisasi. Nilai koefisien jalur (path) Kepuasan 
karyawan ke komitmen Organisasi sebesar 0,441 dan nilai t-statistik sebesar 4,146 (> $\mathrm{t}$ - tabel 1,96). Penelitian ini sesuai dengan yang dilakukan oleh (Tri Maryani, 2018), (Ni Luh Sili Antari, 2019), (Djamhur Hamid, \& Mochammad Djudi, 2016).

\section{KESIMPULAN}

Berdasarkan analisis data dan pembahasan dapat disimpulkan beberapa hal sebagai berikut : Lingkungan Organisasi, Budaya Organisasi berpengaruh signifikan dan positif terhadap Kepuasan Kerja pada karyawan PT. Wahyu Daya Mandiri Surabaya. Budaya Organisasi dan Kepuasan Kerja berpengaruh signifikan dan positif terhadap Komitmen Organisasi pada karyawan PT. Wahyu Daya Mandiri Surabaya.

Dengan demikian manajamen senantiasa memberikan perhatian akan faktorfaktor yang seimbang dalam menjaga dan meningkatkan komitmen karyawan untuk mencapai sasaran perusahaan.

Berdasarkan hasil analisis dan kesimpulan yang diperoleh, saran-saran yang diajukan adalah : Mengingat pentingnya peranan SDM dalam organisasi untuk mencapai tujuan yang telah ditetapkan, maka PT. Wahyu Daya Mandiri Surabaya harus dapat mengembangkan dan memanfaatkan potensi pada setiap karyawan dengan memperhatikan faktor-faktor lingkungan organisasi, budaya organisasi dan kepuasan karyawan.

\section{DAFTAR PUSTAKA}

Agustina Wijayanty. (2018). Pengaruh gaya kepemimpinan transaksional dan lingkungan kerja terhadap kepuasan kerja anggota Polri di Polres Tanjung Jabung Barat. Jurnal Manajemen Jambi, 1(2), 58-68.

Amirul Fahmi, \& Misti Hariasih. (2016). Pengaruh Motivasi, Pengalaman Kerja Dan Lingkungan Kerja Terhadap Prestasi Kerja Guru SMK Muhammadiyah 1 Ngoro Jombang. Jurnal Bisnis, Manajemen \& Perbankan, 2(2), 121-140.

Apriliana Rahmawati., Syarifah Hudayah., \& Fitriadi. (2019). Pengaruh kepemimpinan dan budaya organisasi serta karakteristik pekerjaan terhadap kepuasan kerja dan motivasi. Jurnal Manajemen, 11(2), 103-115.

Dessler, Gary., 1997. Manajemen Sumber Daya Manusia. Jakarta: Pt. Prehallindo

Dwiyekti Agung Nugroho. (2011). Pengaruh budaya organisasi dan gaya kepemimpinan transformasional terhadap komitmen organisasi dan kinerja pegawai (Studi Pada Pusat Pengembangan danPemberdayaan Pendidik dan 
Tenaga Kependidikan/Vocational Education Development CenterMalang). Jurnal Manajemen Bisnis, 1(2), 167-176.

Erni Aprida Hasibuan, \& Afrizal. (2019). Analisis pengaruh kompetensi, lingkungan kerja, dan kompensasi terhadap kepuasan kerja dan implikasinya terhadap kinerja aparatur sipil negara. Jurnal Ekonomi Dan Manajemen STIE Pertiba Pangkalpinang, 5(1), 22-41.

Ghozali and H. Latan, Partial Least Squares: Konsep, Teknik dan Aplikasi Menggunakan SmartPLS 3.0, Edisi 2. Universitas Diponegoro, 2015

Ni Luh Sili Antari. (2019). Pengaruh kepuasan kerja terhadap komitmen organisasiI dan turnover intention (studi pada Losari Hotel Sunset Bali). Prospek: Jurnal Manajemen Dan Bisnis, 1(1), 31-37.

Rina Maretasari. (2016). Pengaruh budaya organisasi dan kepuasan kerja terhadap komitmen organisasi pada karyawan PT. Mandiri Tunas Finace. Jurnal Ekonomi Dan Manajemen, 17(2).

Susanty, Ety, 2013. Pengaruh Iklim Organisasi Terhadap Kepuasan Kerja Dan Komitmen Karyawan Pada Universitas Terbuka. Jurnal Organisasi Dan Manajemen, 8(2), Pp:121-134.

Tri Maryani. (2018). Kontribusi kepuasan kerja dan keterlibatan kerja terhadap komitmen organisasi pada karyawan. Jurnal Ilmiah Psikologi, 11(1), 74-82. 